\title{
The Importance of Food Date Label Among Malaysian Grocery Shoppers
}

Anida Mahmood, Haswira Nor Mohamad Hashim, Siti Sarah Sulaiman, Ahmad Sabirin Zoolfakar, Fazlin Mohamed Zain

To Link this Article: http://dx.doi.org/10.6007/IJARBSS/v12-i1/11359 DOI:10.6007/IJARBSS/v12-i1/11359

Received: 15 November 2021, Revised: 20 December 2021, Accepted: 30 December 2021

Published Online: 06 January 2022

In-Text Citation: (Mahmood et al., 2022)

To Cite this Article: Mahmood, A., Hashim, H. N. M., Sulaiman, S. S., Zoolfakar, A. S., \& Zain, F. M. (2022). The Importance of Food Date Label Among Malaysian Grocery Shoppers. International Journal of Academic Research in Business and Social Sciences, 12(1), 55-64.

Copyright: (C) 2022 The Author(s)

Published by Human Resource Management Academic Research Society (www.hrmars.com)

This article is published under the Creative Commons Attribution (CC BY 4.0) license. Anyone may reproduce, distribute, translate and create derivative works of this article (for both commercial and non0-commercial purposes), subject to full attribution to the original publication and authors. The full terms of this license may be seen at: http://creativecommons.org/licences/by/4.0/legalcode

Vol. 12, No. 1, 2022, Pg. $55-64$

Full Terms \& Conditions of access and use can be found at http://hrmars.com/index.php/pages/detail/publication-ethics 


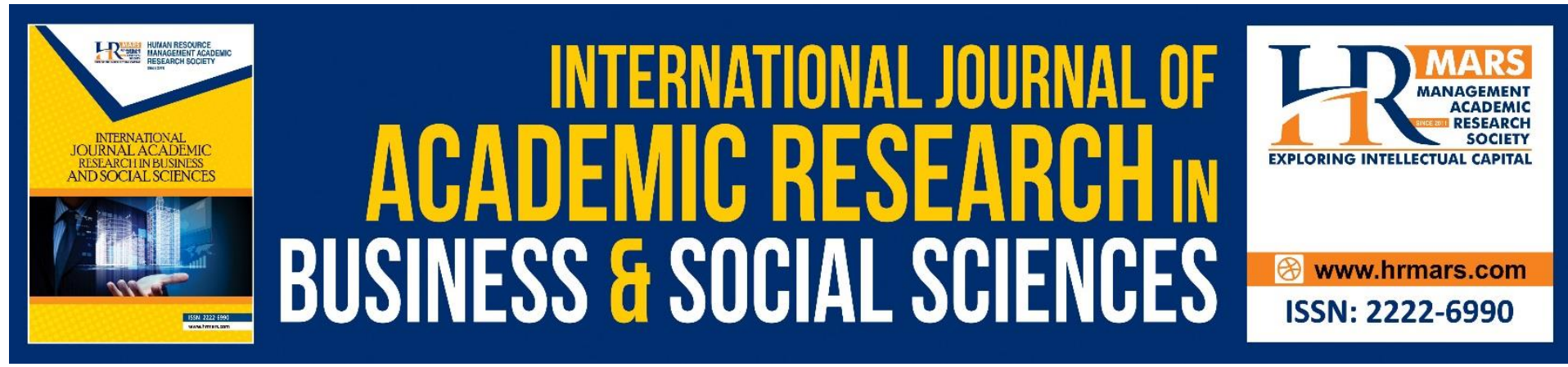

\title{
The Importance of Food Date Label Among Malaysian Grocery Shoppers
}

\author{
Anida Mahmood ${ }^{\mathrm{a}}$, Haswira Nor Mohamad Hashimb ${ }^{\mathrm{b}}$, Siti Sarah \\ Sulaiman ${ }^{\mathrm{c}}$, Ahmad Sabirin Zoolfakard, Fazlin Mohamed Zain ${ }^{\mathrm{e}}$ \\ a Faculty of Law, UiTM Shah Alam, Selangor, Malaysia, 'bCorresponding Author, \\ Faculty of Law, UiTM Shah Alam, Selangor, Malaysia, 'Faculty of Law, UiTM Shah \\ Alam, Selangor, Malaysia, dCollege of Engineering, UiTM Shah Alam, Selangor, \\ Malaysia, ${ }^{\mathrm{E} F a c u l t y}$ of Law, UiTM Shah Alam, Selangor, Malaysia \\ Email: aswira648@salam.uitm.edu.my
}

\begin{abstract}
This paper reports a study which investigates the importance of food date label among Malaysian grocery shoppers. Food safety regulations all over the world require food producers, manufacturers, and retailers to mark their products with date labelling as indicator of safety and fitness. Date labelling approach is used to supply the information to the consumers in making decision to purchase and when to consume the food. In Malaysia, date labelling requirement has been codified in the Food Act 1983, Food Regulations 1985, Consumer Protection Act 1999, and Sale of Goods Act 1957 and is an important component of food safety regulations. Unlike nutrition label, which is widely studied, there is yet a study on the importance placed by the Malaysians on food date label during grocery shopping. To fill in the gap, this study has conducted a nationwide survey on Malaysian adults who did online and conventional grocery shopping at least once a month. An online cross-sectional survey using a 5-point Likert scale was conducted involving 460 respondents using convenience sampling technique. The findings of the survey help to provide an insight on the importance placed by the Malaysian consumers on food date label during grocery shopping. This paper provides a suggestion for the formulation of a specific and targeted measures to enhance the importance of food date label among Malaysian grocery shoppers.
\end{abstract}

Keywords: Food Safety, Legislation, Date Label, Grocery Shoppers, Consumers' Behavior

\section{Introduction}

Food label affixed on the food packaging provides a wealth of information to the consumers to decide which food to choose or avoid. Apart from nutritional facts and ingredients, food label also provides vital information on products dates that helps the consumers to decide on which foods to buy or consume at a certain date (Klemm, 2019). Product dates that are labelled on food packaging may use "Open Dating" approach which is a calendar date that informs consumers and retailers of the date up to which they can expect the food to retain its desired quality and flavor. Open Dating serves as passive communication tool that informs the consumers for how long a food might last. This approach helps the consumer to decide 
when to purchase or use the product by for best quality. The date printed on the food date label using Open Dating approach may be based on product quality and/or food safety as determined by the manufacturer or retailer. Dates on food labels are the food producers and manufacturers' advice to the consumers about how long a food will taste freshest and when the food quality is expected to gradually decline (Dow, 2020). The most common terms indicating Open Dating are "Best Before", "Use By" or "Expires On" printed on food packaging or sticker labels (Klemm, 2019). In addition to Open Dating, the food producers and manufacturers also adopt "Closed Dating as part of food date labelling approach. "Closed Dating" is a series of production numbers used by the manufacturer to indicate when a product was made. The Closed Dating is useful for product recall and traceability purposes (Newsome et al, 2020). Most food date labelling adopts both Open Dating and Closed Dating approaches to provide complete information to the consumers at the point of sale and consumption.

Similar to nutritional and ingredient labels, food date label has become a legal requirement in food safety and consumer protection laws in most countries (Martinelli, 2018). Food safety regulations all over the world require food producers, manufacturers, and retailers to mark their products with date label as indicator of safety and fitness. In Malaysia, this duty of care has been codified in the Food Act 1983, Food Regulations 1985, Consumer Protection Act 1999 and Sale of Goods Act 1957 and is an important component of food safety regulations. Reg. 14 of the Food Regulations 1985 imposed an obligation for date labelling on food packaging signifying the expiry date or the date of minimum durability of that food. Further, s 67 of Consumer Protection Act 1999 (Act 599), recognizes the use of any mark in relation to the products, that may include date labelling, as indicator of safety and fitness. In addition, ss 15 and 16 of the Sale of Goods Act 1957 (Act 382), require the seller and manufacturer to ensure goods sold are fit for purpose, correspond with description given on the good and for the goods to have merchantable quality. These legal requirements place a legal duty on the food producers, manufacturers, and retailers to ensure foods supplied to the consumers not to fall below the required standard. To the consumers, what amounts to be below the required standard is perceived by referring to date labelling marked on the food as referred to in Food Regulations 1985.

\section{Literature Review}

Extant literature reports widespread confusion and misinterpretation on the meaning and function of food date label among consumers all over the world (Kavanaugh, 2020; Colart \& Interis, 2018). Despite the low level of public knowledge and understanding on food date labeling, local study on food labelling are more focused on investigating the importance of nutrition label on food packaging to the consumers (see, Sariman, 2020; Ambak et al., 2018; Jefrydin et al., 2019; Ponnudurai et al., 2019; Rahamat, 2019; Zainol et al., 2019; Teng et al., 2017). Previous studies consistently conclude that the significant role of nutrition label is to provide information on the nutrition content of food products and assist the consumers to make informed decision while purchasing a product (Zainol et al., 2019). Whilst the importance of nutrition label has been firmly established, there is yet local or international study that reports on the importance of food date label among Malaysian consumers or grocery shoppers in Malaysia. This paper argues that investigating the importance of food date label to the Malaysian consumers is critical as food date label provides a different set of information to the consumers. Compared to nutrition label that provides information that 
enables the consumers to choose food that could enhance their health and suitable to their diet, food date label enables the same consumers to make informed decision on the fitness, quality and merchantability of the food products. Lack of importance placed on food date label may lead to edible food waste (Toma et al., 2020) or consumption of inedible food that causes poisoning (Hart, 2020). Recent study in Malaysia reports that in Malaysian consumers would rather forego health aspects to buy cheaper products (Zainol et al., 2019). However, it is still unknown whether the grocery shoppers in Malaysia are willing to compromise safety and quality for cheaper food or bargain price. It is also unknown whether to what extent the Malaysians perceive food date label as important determinant in making purchases at online or conventional grocery stores. This study fills in the gap left by previous studies by investigating the importance of food date label among Malaysian grocery shoppers. It attempts to answer the question: How important is food date label among Malaysian grocery shoppers?

\section{Research Methods}

This study is classified as exploratory research since its aim is to investigate the importance of food date label among Malaysian grocery shoppers. This study employs a field work data collection method using a survey questionnaire involving 460 respondents. A self-developed survey questionnaire was used as an instrument to answer the research question. A survey questionnaire was prepared in English and Malay versions and is divided into six sections. Part $B$ of the questionnaires was designed to meet the objective of this study. This part contained 5 statements, based on a five-point Likert scale ranging from the lowest to the highest. A pilot study to determine the reliability and consistency of the survey questionnaire was conducted upon receiving ethics approval from the Research Ethics Committee (REC) of Universiti Teknologi MARA. The respondents of the pilot study took between 10 minutes to 15 minutes to answer the questions in either English or Malay. The pilot study that involved 100 respondents returned with a Cronbach alpha value $>0.6$ indicating the reliability and consistency of all the statements contained in the survey questionnaire. The feedback from the pilot study was used to improve the questionnaire in terms of its length, choice of words and arrangement of the questions. Once the items in the survey questionnaire were validated, data collection involving the target population was conducted in April 2021. The unit of analysis is the Malaysian household consumers. The target population are adult members of Malaysian households. As of 2020, there were 8 million households in Malaysia. (Department of Statistic Malaysia). The minimum required sample size based on the total population is 385 participants, calculated to have a 5\% margin of error and $95 \%$ confidence level. The sample size was determined based on (Krejcie \& Morgan Table, 1970). To ensure consistency and reliability, this study only includes Malaysian household members that currently reside in Malaysia and used to do grocery shopping. This survey excludes minors, consumers who are on a holiday/business trip in Malaysia, and those who are unable to understand Bahasa Malaysia or English. To avoid sampling error, the demographic section of the survey questionnaire collects data on age, country of residence and frequency of grocery shopping. A convenience sampling technique was used for data collection. This sampling technique was used as the survey questionnaire will be distributed by hand as well as online via email or social media. The online method of data collection was employed due to the Movement Control Order (MCO) currently enforced in Malaysia. IBM SPSS software was used as a tool for quantitative data analysis. Descriptive analysis comprising of mean, median and 
mode were used to determine the importance of food date labelling among Malaysian grocery shoppers.

\section{Findings}

The survey collected data from 460 which is 20 percent higher than the sample size recommended in the sampling schedule by Krejcie and Morgan (1970). The additional respondents were to cater the non-responses and other constraints to fulfil the assumptions of sample size for statistical analysis. The figures below illustrate the findings of the survey conducted with 460 respondents for the purpose of investigating the importance of food date label among Malaysian grocery shoppers.

Demographic analysis indicates that respondents' age is fairly distributed between below 25 years old (22.4\%), below 35 years old (24.3\%), below 45 years old (22.2) and below 55 years old (22.6\%). Majority (89.8\%) of them currently live with their family members. The remaining respondents (11\%) either live alone or share accommodation with non-family members in a rented house or hostel. Almost half of the respondents (49.8\%) reported that they have five persons or more household members staying with them. The distribution of respondents according to their monthly gross income indicates that 26.8 percent of the respondents come from B40 group, while 33.3 percent come from T20 group. The M40 group represented by 40 percent of the population. Most respondents shopped for their groceries once a week $(41.7 \%)$ while less than 15 respondents (3.3\%) did their grocery shopping daily. Respondents also reported that they mostly did their grocery shopping at hypermarket $(64.3 \%)$ while only $6.3 \%$ (29) respondents shopped at wet markets. More than half of the respondents $(68.3 \%)$ preferred in-store grocery shopping mode than online shopping (3\%). The remaining respondents (28.7\%) preferred to combine in-store and online grocery shopping mode. Tables below depict the frequency of grocery shopping, the most common place for grocery shopping and the preferred mode of grocery shopping among the respondents.

\begin{tabular}{|l|l|l|l|l|l|}
\hline \multicolumn{2}{|c|}{} & Frequency & Percent & Valid Percent & $\begin{array}{l}\text { Cumulative } \\
\text { Percent }\end{array}$ \\
\hline \multirow{4}{*}{ Valid } & Everyday & 15 & 3.3 & 3.3 & 3.3 \\
\cline { 2 - 6 } & Once a week & 192 & 41.7 & 41.7 & 45.0 \\
\cline { 2 - 6 } & Twice a week & 120 & 26.1 & 26.1 & 71.1 \\
\cline { 2 - 6 } & Every two weeks & 93 & 20.2 & 20.2 & 91.3 \\
\cline { 2 - 6 } & Once a month & 40 & 8.7 & 8.7 & 100.0 \\
\hline
\end{tabular}

Table 1. Frequency of grocery shopping

\begin{tabular}{|c|c|c|c|c|c|}
\hline & & Frequency & Percent & Valid Percent & $\begin{array}{l}\text { Cumulative } \\
\text { Percent }\end{array}$ \\
\hline \multirow[t]{5}{*}{ Valid } & Wet market & 29 & 6.3 & 6.3 & 6.3 \\
\hline & Grocery store & 98 & 21.3 & 21.3 & 27.6 \\
\hline & Convenience store & 37 & 8.0 & 8.0 & 35.7 \\
\hline & Hypermarket & 296 & 64.3 & 64.3 & 100.0 \\
\hline & Total & 460 & 100.0 & 100.0 & \\
\hline
\end{tabular}

Table 2. The place the respondents mostly do their grocery shopping in Malaysia 
INTERNATIONAL JOURNAL OF ACADEMIC RESEARCH IN BUSINESS AND SOCIAL SCIENCES Vol. 12, No. 1, 2022, E-ISSN: 2222-6990 @ 2022 HRMARS

\begin{tabular}{|l|l|l|l|l|l|}
\hline \multicolumn{2}{|c|}{} & & & & Fumulative \\
\hline \multirow{3}{*}{ Valid } & In store & 314 & 68.3 & 68.3 & 68.3 \\
\cline { 2 - 6 } & Online & 14 & 3.0 & 3.0 & 71.3 \\
\cline { 2 - 6 } & Both & 132 & 28.7 & 28.7 & 100.0 \\
\cline { 2 - 6 } & Total & 460 & 100.0 & 100.0 & \\
\hline
\end{tabular}

Table03. Respondents' preferred mode of grocery shopping.

A five items questionnaire were used to investigate the importance of reading the food date label before grocery shopping. The importance of food date labeling is measured by asking the respondents how frequent they check on date label before grocery shopping and before buying grocery with special offer/best price/discount, their preference on buying food that has date label and their attitudes towards buying food that does not have date label. Likert scale is used to depict the level of importance of food date label among the respondents. The Likert scale used are as follows: 1=Never, 2=Rarely, 3=Sometimes, 4= Most of the time, $5=$ Every time. The summary of the analysis is presented in Tables below.

\begin{tabular}{|l|l|l|l|}
\hline Statement & N & Mean & $\begin{array}{l}\text { Std. } \\
\text { Deviation }\end{array}$ \\
\hline I read the product information before grocery shopping & 460 & 3.78 & .917 \\
\hline I check on date label before grocery shopping & 460 & 4.29 & .869 \\
\hline $\begin{array}{l}\text { I check on date label before buying grocery with special offer/best } \\
\text { price/discount }\end{array}$ & 460 & 4.32 & .882 \\
\hline I prefer buying food that has date label & 460 & 4.43 & .836 \\
\hline I would still buy food that does not have date label & 460 & $\begin{array}{l}3.760 \\
9\end{array}$ & 1.24695 \\
\hline Overall mean for grocery shopping habit & 460 & $\begin{array}{l}4.116 \\
5\end{array}$ & .61823 \\
\hline
\end{tabular}

Table 4. Mean and Std. Deviation of the Importance of Food Date Label among Malaysian Grocery Shoppers

Table 4 above presents the means and standard deviations of the importance of food date label among Malaysian grocery shoppers. Considering all the five statements together, the mean score of 4.12 implies that, on the average, the respondents perceived food date label as important. Among the five statements, most of the time the respondents I prefer buying food that has date label (Mean=4.43). These are followed, in descending order, by elements contained in the statements / check on date label before buying grocery with special offer/best price/discount (Mean=4.32), I check on date label before grocery shopping (Mean=4.29), I read the product information before grocery shopping (Mean=3.78) and I would still buy food that does not have date label (Mean=3.76).

The study uses various statements to gauge the perceptions of respondents on the importance of food date label. The use of the statements to measure respondents' perceptions requires that these statements be reliable or consistent. Reliability tests were carried out on the statements of each dimension, the result of which is summarized in Table 05. 


\begin{tabular}{|l|l|l|}
\hline Dimension & $\begin{array}{l}\text { No of } \\
\text { statements }\end{array}$ & Cronbach's Alpha \\
\hline Importance of food date label & 5 & 0.645 \\
\hline
\end{tabular}

Table 5. Cronbach's Alpha by Dimension

The Cronbach's alpha value is high, at 0.645 , implying that the statements reliably measure the perceptions of the respondents on the five statements contained in the dimension.

\section{Discussion}

Based on the findings, it can be summed up that on average the Malaysian grocery shoppers perceived food date label as important. As the survey includes grocery shoppers currently resides in Malaysia, this study covers both citizens and permanent residents of Malaysia. The survey only includes individuals aged 18 years old and above, which considered as the age category that can make rational considerations in purchasing. However, the findings can be generalized to all age populations in Malaysia as this is a nationwide survey that that has an almost equal representations of five categories of age that are known to be actively involved in grocery shopping. The findings are also valid since $71.1 \%$ of the respondents did grocery shopping either every day, once a week or twice a week. However, the findings of the present study cannot be generalized to online grocery shoppers since only $3 \%$ of the respondents preferred online grocery shopping. Despite the limitation, the findings are consistent with the result of a study conducted by Ambak et al (2018) that expiry date was the most frequently read information on food date label. Compared to the former, the present study includes grocery shoppers' preference and attitude towards buying food with and without date label as additional factors to measure the importance of food date label among Malaysian grocery shoppers.

The findings from this study also suggest that food date label is an important determinant in making purchases at in store grocery stores. The findings of this study further suggest that most respondents were extra careful in checking date label before they buy grocery with special offer/best price/discount. These findings marked a paradigm shift in the Malaysian consumers' behavior and attitudes on food labels since in a study conducted in 2013 conducted by Latiff (2013) on the effects of food label on consumers purchasing behavior concluded that Malaysian consumers did not always refer to a label on food product. In addition, the findings of this study reject earlier assumption that Malaysian consumers are willing to compromise safety and quality for cheaper food or bargain price. This finding is also contrary to the previous study that found Malaysian consumers would rather forego health aspects to buy cheaper products (Zainol et al., 2019). The Malaysian grocery shoppers' positive attitude and treatment towards food date label is an indication of their high level of knowledge and awareness on food date labelling. This assumption finds support from a local study on nutrition label made by Zainol et al (2019) that finds significant positive effect of health knowledge on attitude towards nutrition label and attitude towards nutrition label on healthy food choice. This assumption is also consistent with the findings made by Jefriydin et al (2019) who identify personal factors such as knowledge, misperception, awareness, and trust significantly impact how the respondents check and read food packaging labels.

The respondents' positive behavior of checking and reading food date labelling and preferring food with date label could be explained using the Theory of Planned Behavior proposed by 
Ajzen and Fishbein (Ajzen, 1991). The theory posits that behavior is determined by their intentions, attitudes, and beliefs of an individual as well as the subjective norms perceived by the individual (Schmidt, 2019). This theory also suggests that individuals make logical, reasoned decisions to engage in specific behaviors by evaluating the information available to them (Neighbors et al., 2013). As majority of the respondents claimed that they check and read food date label most of the time, the assumption is the respondents have sufficient knowledge and information on the function of date label on food and the consequences of ignoring the date label. This assumption is line with the behavioral belief principle that forms part of the theory. Further, by applying the control beliefs principle imbedded in the theory, it could also assume that the respondents do not perceive checking or reading the information on food date label as easy and not difficult.

\section{Conclusion}

This study has achieved its aim to investigate the importance of food date label among Malaysian grocery shoppers. The major finding of this study indicates that food date label serves as an important determinant among the Malaysian grocery shoppers or consumers when making decision to purchase the foods. The consumers would check and read the date label marked on the food before making their purchase. The finding also supports the previous study by Ambak, et.al (2018) who found out that expiry date was the most frequently read information on food label among the consumers surveyed. Despite the positive outlook on the importance of food date labelling, there are still respondents whowould not mind buying food that does not have date label. Therefore, the Malaysian consumers need to be educated on the risks of purchasing certain types of food that will rapidly deteriorate once they passed the labelled date. Future research should attempt to investigate the importance of food date label based on specific categories of food i.e., vegetables; fruits; breads, cereals, rice, pasta, noodles; grains, legumes, nuts and seeds; meat and poultry, fish and seafood; milk, yoghurt, cheese; dairy foods and eggs; and fermented food. Investigating the importance of food date labels based on categories of food is deemed important as decades of scientific study reports different stage of fitness and merchantable quality among these categories of food (Michaud, 2017; Tsiros \& Heilman, 2005; Harbor-Locure et al, 2001).

Future research should also make a distinction on the importance placed by consumers on foods that subjected to date label law, and those not governed under any law. The findings could assist the policy makers determine further interventions on the segment of population who are less likely to place a high degree of importance on food date labeling by increasing their awareness on the importance of checking, reading, and preferring to buy foods that have date label. It is suggested that the awareness campaign is targeted at male, non- tertiary academic achievers and rural populations. This suggestion is based on the results of previous studies by Ambak et al, (2018) and Ponnudurai et al. (2019) that report these groups of population are less likely to place a great importance on date labels compared to the urban population. This study is part of the larger study that investigates for evidence based legislative reform on food date labelling in minimizing edible food waste. Hence, the findings of this study could also become a reference point to food safety regulators in proposing a legislative reform on food date labeling to minimize edible food waste amongst Malaysian population. 


\section{Acknowledgments}

This paper is derived from research titled "An Investigation for Evidence-Based Legislative Reform On Food Date Labelling In Minimizing Edible Food Waste". The writers thank Universiti Teknologi MARA (UITM) for awarding a research grant (600-RMC/GPK 5/3 (034/2020) and supporting the publication of this paper.

\section{References}

Ajzen, I. (1991). The theory of planned behavior. Organizational Behavior and Human Decision Processes, 50(2), 179.

Ambak, R., Tupang, L., Hasim, M. H., Salleh, N. C., Zulkafly, N., Salleh, R., . . Naidu, B. M. (2018). Who Do Not Read and Understand Food Label in Malaysia? Findings from a Population Study. Health Science Journal, 12(1), 548. doi:10.21767/1791-809X.1000548

Bryła, P. (2020). Who Reads Food Labels? Selected Predictors of Consumer Interest in Frontof-Package and Back-of-Package Labels during and after the Purchase. Nutrients, 12, 2605. doi:10.3390/nu12092605

Carter-Weis, Narang, A., Rickard, B., \& Souza-Monteiro, D. M. (2021). Effects of Date Labels and Freshness Indicators on Food Waste Patterns in the United States and the United Kingdom. Sustainability, 13, 7897. doi: https://doi.org/10.3390/su13147897

Collart, A. J., \& Interis, M. G. (2018). Consumer Imperfect Information in the Market for Expired and Nearly Expired Foods and Implications for Reducing Food Waste. Sustainability, 10, 3835. doi::10.3390/su10113835

Dow, C. (2020). What do the date labels on food actually mean? Retrieved from https://www.nutritionaction.com/daily/food-safety/what-do-the-date-labels-on-foodactually-mean/

Harbor-Locure, A. L., McLean-Meyinsse, P. E., \& Bethea, V. V. (2001). Label Use and Importance Rankings for Selected Milk Labeling Attributes. Journal of Food Distribution Research, 32(3), 55.

Hart, K. (2020). This Is What Really Happens When You Eat Expired Food. Mashed. Retrieved from https://www.mashed.com/232887/this-is-what-really-happens-when-you-eatexpired-food/

Jefrydin, N., Nor, N. M., \& Talib, R. A. (2019). Nutrition labelling: an exploratory study on personal factors that influence the practice of reading nutrition labels among adolescents. Mal J Nutr, 25(1), 143. doi:https://doi.org/10.31246/mjn-2018-0123

Kavanaugh, M., \& J.Quinlan, J. (2020). Consumer knowledge and behaviors regarding food date labels and food waste. Food Control, 115, 107285.

Klemm, S. (2019). Understanding Dates on Food Labels. Academy of Nutrition and Diabetics. Retrieved from https://www.eatright.org/

L.W.Wilson, N., J.Rickard, B., Saputo, R., \& Ho, S.-T. (2017). Food waste: The role of date labels, package size, and product category. Food Quality and Preference, 55, 35.

Latiff, Z. A. A. (2013). Effects of Food Label on Cosumers Purchasing Behavior in Malaysia. (DPhil), Universiti Putra Malaysia, Retrieved from http://psasir.upm.edu.my/id/eprint/40732/1/FP\%202013\%2037\%20UPM.pdf

Martinelli, K. (2018). Why is Food Labelling Important? Hub. Retrieved from https://www.highspeedtraining.co.uk/hub/importance-of-food-labels/

Michaud, P. (2017). 20 foods you should never eat past their expiration date. MSN. Retrieved from https://www.msn.com/en-us/health/wellness/20-foods-you-should-never-eatpast-their-expiration-date/ss-BBF3Wfz 
Neighbors, C., Foster, D. W., \& Fossos, N. (2013). Peer Influences on Addiction (1 ed.): Academic Press.

Newsome, R., Balestrini, C. G., Baum, M. D., \& Corby, J. (2014). Applications and Perceptions of Date Labeling of Food. Comprehensive Reviews in Food Science and Food Safety 13(4), 745. doi:10.1111/1541-4337.12086

Azman, N. S. Z. S. (2014). Nutritional Label and Consumer Buying Decision:A Preliminary Review. Procedia - Social and Behavioral Sciences, 130, 490

Norman, P., \& Conner, M. (2017). Health Behavior. Retrieved from https://app.dimensions.ai/details/publication/pub.1090903335

Ponnudurai, N. A. P., Ghazi, H. F., \& Abdalqader, M. A. (2019). Usage of food label information among supermarket shoppers in Shah Alam, Malaysia. International Journal of Medical Toxicology and Legal Medicine, 22(1-2), 118. doi:10.5958/0974-4614.2019.00027.5

Rahamat, S. (2019). Influence of Malaysian consumers' intentions and use of menu labeling on purchase behavior. (DPhil), lowa State University, Retrieved from https://lib.dr.iastate.edu/cgi/viewcontent.cgi ?article=8088\&context=etd

Sariman, S. (2020). Associations of Knowledge, Attitude and Practices of Food Label on Cardiovascular Diseases (CVD) Risk amongst University Students in Selangor, Malaysia. Journal of Nutritional Science and Vitaminology, 66(Supplement), 275. doi:10.3177/jnsv.66.S275

Schmidt, K. (2019). Predicting the consumption of expired food by an extended Theory of Planned Behavior. Food Quality and Preference, 78, 103746.

Teng, N. I. M. F., Zin, M. B. M., \& Zakaria, N. B. (2017). Groceries shopping practices and diet quality among Malaysian. International Journal of Collaborative Research on Internal Medicine \& Public Health, 9(7), 700.

Toma, L., Font, M. C., \& Thompson, B. (2020). Impact of consumers' understanding of date labelling on food waste behaviour. Operational Research, 20, 543.

Tsiros, M., \& Heilman, C. M. (2005). The Effect of Expiration Dates on the Purchasing Behavior for Grocery Store Perishables. Journal of Marketing, 69(2), 114.

Zainol, Z., Yahaya, R., Osman, J., \& Omar, N. A. (2019). The Effect of Health Knowledge, Nutrition Label Use and Attitude towards Nutrition Label on Healthy Food Choice among Malaysian Consumer. International Journal of Academic Research in Business and Social Sciences, 9(9), 1327. doi:10.6007/IJARBSS/v9-i9/6467

Zainol, Z., Yahaya, R., Osman, J., Omar, N. A., Ramdan, M. R., \& Habidin, N. F. (2018). The Role of Nutrition Label among Malaysian Consumer: A Preliminary Review. International Journal of Academic Research in Business and Social Sciences, 8(4), 1031. doi:: http://dx.doi.org/10.6007/IJARBSS/v8-i4/4143 